\title{
Neuromuscular Metamorphosis in the Moth Manduca sexta: Hormonal Regulation of Synapse Loss and Remodeling
}

\author{
James W. Truman and Shirley E. Reiss \\ Department of Zoology, University of Washington, Seattle, Washington 98195
}

The motor system of the moth Manduca sexta is completely remodeled during the pupal-adult transformation (PAT). It is stable until the formation of the pupal stage (0\% PAT), but larval motor end plates become disrupted by $5 \%$ PAT and are lost by $10 \%$ PAT, at the time that the muscle has begun to degenerate. Most of the axonal arbor is retracted by $15 \%$ with the first signs of adult sprouts appearing by $20 \%$ PAT, coinciding with proliferative activity in the remains of the larval muscle. Extensive growth of the axonal arbor begins after $30 \%$ PAT, with an initial phase of rapid longitudinal growth (35-50\% PAT) and then the production of short transverse branches that then form sprays of end plates (50-70\% PAT). Growth and maturation of the end plates occupies the remainder of metamorphosis.

Neuromuscular metamorphosis was interfered with by systemic or local treatment with a mimic of the insect juvenile hormone. The results of these treatments suggest that some aspects of the removal of larval axonal branches requires cues from the target. For the sprouting response, the rapid longitudinal growth over the muscle appears to be due to ecdysteroids acting directly on the cell body of the motoneuron. By contrast, the subsequent production and maintenance of transverse sprouts and the corresponding end plates may be an indirect response to stimulation of muscle growth and differentiation by ecdysteroids.

[Key words: sprouting, synapse elimination, metamorphosis, ecdysteroids, juvenile hormone, Manduca sexta]

Metamorphosis in insects is accompanied by a dramatic reorganization of the nervous system that occurs at the cellular, as well as the organ system level. Although sensory neurons (Levine et al., 1985), interneurons (Sandstrom and Weeks, 1991; Waldrop and Levine, 1992), and motoneurons (Taylor and Truman, 1974; Casaday and Camhi, 1976; Truman and Reiss, 1976; Levine and Truman, 1985; Weeks and Ernst-Utzschneider, 1989; Kent and Levine, 1988) all undergo cellular remodeling, most attention has been given to motoneurons. During the transition from the larva to the adult, many motoneurons prune back larval portions of their dendritic arbors and then grow adult-specific dendritic trees. These dendritic alterations reflect changing pat-

Sept. 29, 1994; revised Jan. 31, 1995; accepted Feb. 3, 1995.

We thank Prof. Lynn Riddiford for the methoprene and for many helpful discussion through the course of this project. We thank Lynn Riddiford and Carol Wright for a critical reading of the manuscript. The research was supported by Grant NS13079 from NIH.

Correspondence should be addressed to Dr. James W. Truman, Department of Zoology, NJ-15, University of Washington, Seattle, WA 98195.

Copyright (c) 1995 Society for Neuroscience 0270-6474/95/154815-12\$05.00/0 terns of connectivity as these cells function first in the larva, then in the pupa, and finally in the adult (e.g., Levine and Truman, 1982; Jacobs and Weeks, 1990). These motoneurons also undergo profound changes in the periphery as they lose their larval muscles and acquire new, adult muscles (Levine and Truman, 1985; Weeks and Ernst-Utzschneider, 1989; Kent and Levine, 1988). The larval and adult targets of a given neuron may vary dramatically in size, orientation, and biophysical properties (Rheuben and Kammer, 1980; Nüesch, 1985). The larval muscle degenerates early in metamorphosis, but its remains are transformed into an anlage that will grow to form the adult muscle (Nüesch, 1985). Using methylene blue staining to follow the changes in the innervation of the flight musculature during metamorphosis of the moth Antheraea polyphemus, Heinertz (1976) saw that the flight motoneurons remain in contact with their target throughout this transition. During this process, however, larval axonal arbors are lost and new adult arbors are subsequently formed.

The remodeling of neurons during metamorphosis is under the control of the steroid hormones, the ecdysteroids, acting in the absence of juvenile hormone (JH) (Truman 1988; Levine et al., 1991). The results of local application of either ecdysteroids, or JH mimics (to block ecdysteroid action) to identified sensory neurons suggest that the hormonal environment of the cell body determincs whether or not a sprouting response occurs (Levine et al., 1986; Levine 1990). The fact that ecdysteroids act directly on neurons to induce sprouting was subsequently demonstrated for cultured leg motoneurons in Manduca. Sprouting by these isolated cells depends only on the presence or absence of ecdysteroids. Moreover, the steroid-induced sprouting is blocked by addition of JH mimics (Prugh et al., 1992).

Although these studies show that ecdysteroids play a prominent role in inducing growth responses in motoneurons, they do not exclude a role for local factors in shaping the details of that growth. The complexity of the CNS makes fine manipulation of the dendritic environment problematical. Conditions in the periphery, though, are simpler consisting of the motoneuron, its target muscle, and associated glia. The periphery is also more accessible to experimental manipulation. Consequently, we have undertaken an analysis of the changes in the neuromuscular system of Manduca sexta during metamorphosis. We find that during this period, the axonal arbors of motoneurons undergo dramatic synapse elimination and regression followed by sprouting and regrowth. Different aspects of the regression and the regrowth appear to represent direct and indirect responses of the motoneurons to the hormonal signals that drive metamorphosis.

\section{Materials and Methods}

Experimental animals. Larvae of the tobacco hornworm, Manduca sex$t a$, were reared in individual cups on an artificial diet at $26^{\circ} \mathrm{C}$ (Bell and 
Joachim, 1978). Most larvae were reared under 17L:7D photoperiod conditions, which insured continuous development to the adult stage. To obtain animals that entered diapause (a state of developmental arrest) after formation of the pupa, we reared some individuals under shortday conditions (12L:12D). The time of pupal ecdysis was noted for each animal. We generally used animals that ecdysed between 2 and 5 hr after lights on. Through the first half of development animals were staged based on the time since pupal ecdysis. For the last half of adult differentiation we used the timetable in Schwartz and Truman (1983). Under our conditions, the period from pupal ecdysis to adult ecdysis was $20 \mathrm{~d}$. The age of the animals is given as the percentage of the time that had elapsed between pupal ecdysis and emergence of the adult (\% of the pupal-adult transformation; $\%$ PAT). Each day is equivalent to 5\% PAT. Measurements and experimental treatments were performed on abdominal segments A4 to A6.

Cell-filling techniques. Abdomens from the appropriate stage were opened ventrally and pinned out flat under saline. The dorsal nerve, which leads to the dorsal musculature, was severed at the level of the spiracle, and the distal stump placed in a small cup made of petroleum jelly that isolated the stump from the remainder of the saline. The cut end of the nerve was treated with distilled water for $1-5 \mathrm{~min}$ and then the water was replaced with a cobaltous lysine complex containing 0.4 $\mathrm{M}$ cobaltous chloride and $1.2 \mathrm{M} \mathrm{L-lysine} \mathrm{(Lazar,} \mathrm{1978).} \mathrm{The} \mathrm{top} \mathrm{of} \mathrm{the}$ cup was sealed over with petroleum jelly to prevent evaporation. Typically, preparations were maintained in a humidified chamber at room temperature for about $4 \mathrm{hr}$ and then at $4^{\circ} \mathrm{C}$ for $2-3 \mathrm{~d}$.

After the axons had filled, the cobalt was precipitated in saline saturated with ammonium sulphide. The cobalt was then intensified using the modified Timm's technique (Bacon and Altman, 1977). These preparations were then dehydrated, cleared in methyl salicylate, and mounted in Canada balsam.

Muscle measurements. Measurements were made on tissue that was fixed in a moderately stretched condition. Some treatments resulted in abnormally shaped muscles that were bulbus at one end and narrow at the other. Consequently, we measured muscle width at two sites, one $25 \%$ of the distance from the origin and the other $25 \%$ from the insertion. The average of these two measurements was then used as the muscle width. For determination of the insertion angle, the muscle was drawn using a camera lucida as was the posterior margin of the segment. The insertion angle was the angle between the longitudinal axis of the muscle and the scgment margin.

The extent of innervation was determined for muscles whose motoneurons had been filled with cobalt ions and intensified. The anterior and posterior limits of the axon arbor were indicated on a drawing of the muscle. The percentage of the length of the muscle covered by innervation was calculated by dividing the distance between these limits by the overall length of the muscle.

Juvenile hormone mimic treatments. Animals were treated with the JH mimic (JHM) methoprene. For systemic treatment, the methoprene was prepared as a slow release formulation dissolved in mineral oil at a concentration of $1 \mu \mathrm{g} / \mathrm{ml}$ and the animals injected with $20 \mu \mathrm{g} / \mathrm{animal}$. Localized treatment utilized the approach of Levine et al., (1986); the methoprene was dissolved in low melting point dental wax at a concentration of $1 \mu \mathrm{g} / \mu \mathrm{l}$ of wax. For application, the wax was heated to its melting point and applied to the fourth or fifth abdominal hemisegment, between the dorsal midline and the lateral spiracle. The JHM is lipid soluble and diffuses through the cuticle to affect underlying tissues. Applications were to pupae of various ages. Typically, after metamorphosis, the resulting adult had a patch of pupal cuticle underlying the site of application. The control half of the segment had its normal investiture of adult scales.

\section{Results}

Metamorphosis of the dorsal abdominal musculature

We focussed on four sets of external muscles situated in the dorsolateral region of abdominal segments A4 to A6 between the dorsal stretch receptor and the heart (Fig. 1). In the larva, these muscles are innervated by three motoneurons. Motoneuron MN-30 innervates muscle DIO, MN-12 innervates muscle DEO1, and MN-1 has a branched axon with a distal branch that supplies DEO2 and a recurrent branch that innervates the dispersed fibers of DEO3 (Levine and Truman, 1985; Truman, unpublished). In addition to their motor innervation, each set of muscles also receives input from one neuromodulatory neuron, a ventral unpaired medial (VUM) neuron.

At the start of the pupal stage, all four muscles were contractile and birefringent. They remained contractile through the first day after pupal ecdysis, but by $48 \mathrm{hr}(10 \%$ PAT) all were degenerating, having lost birefringence and contractility. Each degenerating group varied in its subsequent contribution to the adult musculature (Fig. 1). For DEO1, the most proximal fiber (fiber 1) formed the anlage that regrew to produce the bulk of muscle DE5 with a minor contribution from fiber 2 and little if any from more distal fibers. For DIO, by contrast, the remains of the fibers coalesced into two primary anlagen that participated in the regrowth of DE3. Both reattached to the epidermis at midsegment and the adult muscle formed from the posterior section while the anterior half degenerated. For the two sets of muscles supplied by $\mathrm{MN}-1$, the 3 larval fibers comprising DEO2 regressed and then regrew to form the adult muscle DE4. The multiple fibers of DEO3, that are innervated by the recurrent axon branch, appeared to regress completely.

Our major focus was on DEO1. By 10-15\% PAT, fiber 1 began to show numerous small dividing nuclei while the remaining fibers were mitotically quiescent (C. Wright and Truman, unpublished). Between 35 and $40 \%$ PAT, the anterior portion of this growing anlage migrated across the epidermis to assume the longitudinal orientation of the adult muscle (Table 1). By about $60 \%$ PAT it began to cleave into fibers and to regain its birefringence. The adult muscle (DE5) grew to about $1 \mathrm{~mm}$ in width and contained a large number of small diameter (about $30 \mu \mathrm{m}$ ) fibers.

\section{Reorganization of axon arbors during muscle growth}

We used morphological criteria to identify the end plates. In the larval and adult stages, these appeared as irregular expansions at the ends of fine axonal branches. The mature end plates lacked filipodial extensions that were characteristic of the growing axonal branches seen during the period of sprouting. Although we assume that the end plates are functional (see Rheuben, 1992; Sonea and Rheuben, 1992), we have no data concerning the functional capacity of the endings observed during axonal sprouting. Our analysis concentrates on the reorganization of the arbor of $\mathrm{MN}-12$ as its target DEO1 is being transformed into DE5 (see Figs. 2-4). Data from other neurons are used to illustrate specific points.

$P A T, 5-10 \%$. The anterior and posterior axon branches of MN-12 supply the anterior and posterior halves respectively of the five muscle fibers of DEO1 (Fig. 2). The pattern of major branching over the fibers was stereotyped although variants such as seen in Figure $2(5 \%)$ were frequently observed. The fine axonal branches terminated in irregular sets of zig-zag thickenings that comprise the larval motor end plates (Figs. 3, 4; 0\%). At $20 \mathrm{hr}$ after pupal ecdysis the end plates took on a beaded appearance, and by $26 \mathrm{hr}$, they showed prominent, irregular varicosities (Figs. 3, 4; 5\%). End plates had disappeared by $48 \mathrm{hr}$ (10\% PAT), although the axonal arbor was still at its full extent over the surface of the muscle (Fig. $2 ; 10 \%$ ). The end plates disappeared simultaneously throughout the extent of the arbor. As the end plates were being lost, the fine axon branches became varicose as compared with their earlier uniform diameter (Fig. $4 ; 10 \%)$. The ends of many of the axonal branches had swollen tips (Fig. 3; 10\%) reminiscent of the "retraction bulbs" seen in vertebrate muscle during synapse elimination (Riley, 1977, 1981). 

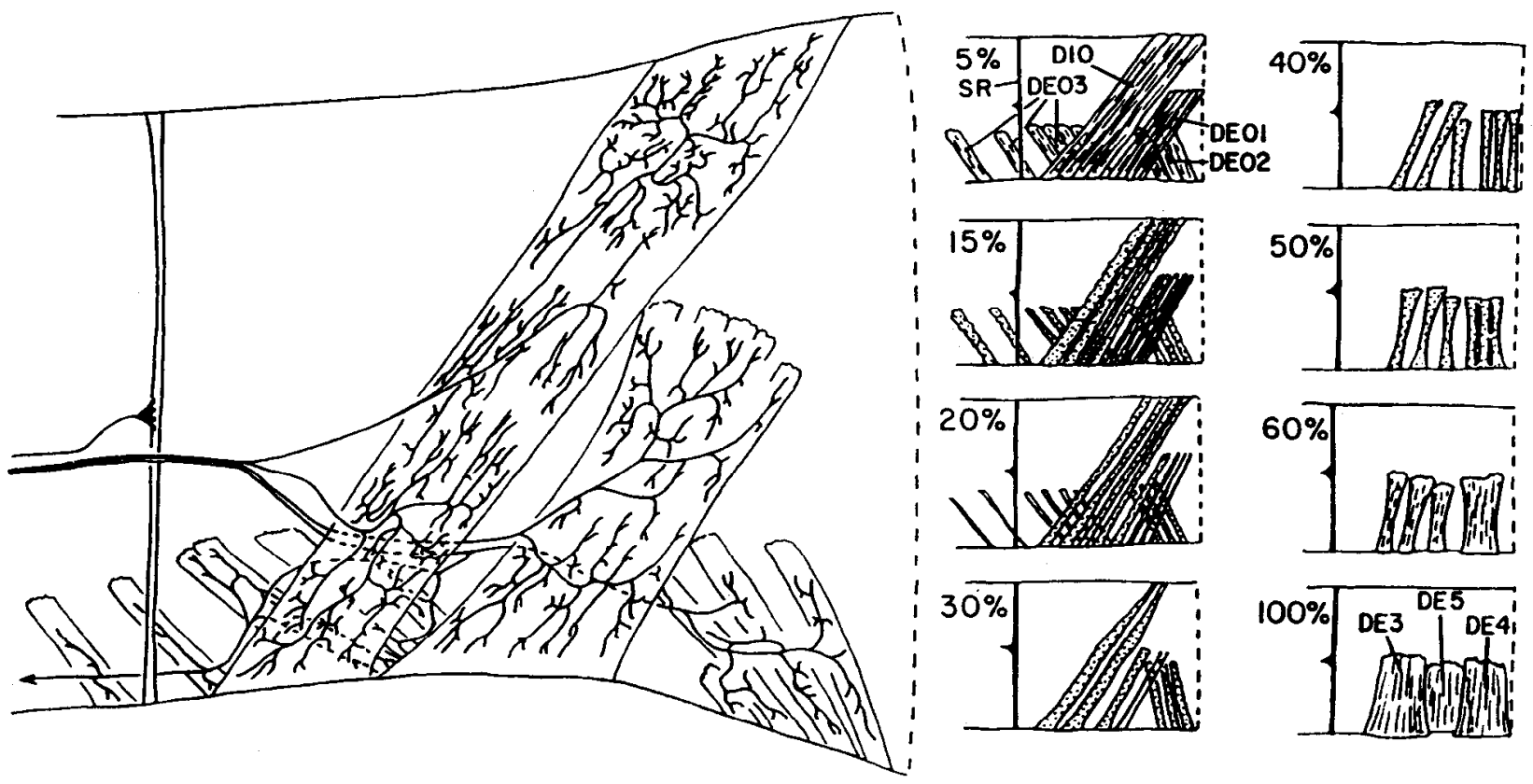

\begin{tabular}{|c|c|}
\hline Motoneuron & $\begin{array}{l}\text { Larval } \\
\text { muscle }\end{array}$ \\
\hline$M N-30$ & DIO \\
\hline$M N-12$ & DEO1 \\
\hline$M N-1$ & $\begin{array}{l}\text { DEO2 } \\
\text { DEO3 }\end{array}$ \\
\hline
\end{tabular}
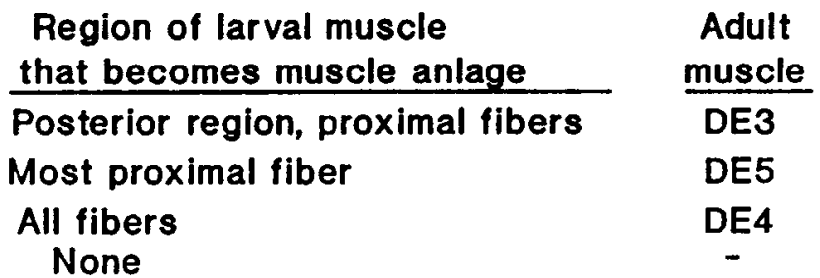

Figure 1. Muscles found in the dorsomedial region of abdominal segment A4. Left, Drawing of the region from an animal shortly after pupal ecdysis showing the muscles and their pattern of innervation by motoneurons MN-30 (to the dorsal internal oblique muscle, DIO), by MN-12 (to dorsal external oblique $1, D E O I$ ), and by $\mathrm{MN}-1$ (to $D E O 2$ and $D E O 3$ ). The axon of the latter extends ventrally beyond the drawing (arrow) to the spiracle. Right, Schematic representation of the changes that occur in the larval muscles as they are converted to the adult muscles; dorsal external 3 (DE3) from DIO, DE4 from DEO2, and DE5 from DEO1. The numbers are the percentage of the pupal-adult transition (PAT) that has been completed. Approximately $5 \%$ per day under our conditions. $S R$, stretch receptor. The table summarizes the relationship of the motoneurons to their larval and adult targets.

PAT, $10-15 \%$. During the next $24 \mathrm{hr}$, the innervation of DEO1 was reduced to contact sites in the middle of fiber 1 (Figs. $2-4 ; 15 \%$ ). In many cases, the axon branch responsiblc for thesc persistent contacts appeared to arise from the main axon at a considerable distance before the muscle. It produced branches

Table 1. Change in the insertion angle of muscle DEO1/DE5 during the pupal-adult transformation

\begin{tabular}{lll}
$\begin{array}{l}\text { Age } \\
\left(\% \mathrm{PAT}^{a}\right)\end{array}$ & $N$ & $\begin{array}{l}\text { Insertion angle } \\
(\text { degrees } \pm \mathrm{SD})\end{array}$ \\
\hline $5 \%$ & 8 & $59 \pm 9$ \\
$10 \%$ & 7 & $54 \pm 5$ \\
$15 \%$ & 8 & $54 \pm 5$ \\
$20 \%$ & 7 & $58 \pm 9$ \\
$25 \%$ & 6 & $63 \pm 13$ \\
$30 \%$ & 7 & $64 \pm 11$ \\
$35 \%$ & 6 & $66 \pm 12$ \\
$40 \%$ & 6 & $90 \pm 11$ \\
$50 \%$ & 6 & $86 \pm 6$ \\
$95 \%$ & 5 & $85 \pm 11$ \\
Diapausing pupa & 6 & $64 \pm 7$ \\
\hline
\end{tabular}

"Percentage of the pupal-adult transformation. over about $500 \mu \mathrm{m}$ of fiber 1 and provided the site of regrowth of the adult axonal arbor. In occasional preparations, a thin process extended from this site to make a contact on fiber 2 or 3 .

The extent and pattern of pruning of the axon arbor was characteristic for a given neuron but differed amongst the different identified cells. As seen above, the axon arbor of MN-12 was severely pruned back to a contact site on the most proximal fiber of its larval target. MN-30, by contrast, lost most or all of its anterior branch, in accord with the eventual loss of the anterior half of DIO. In the case of MN-1, its distal axon branch retained contact with all three fibers of DEO2, but its recurrent branch, that innervated DEO3, became very tenuous and eventually disappeared.

MN-30 and MN-1 lost their larval end plates at the same time as did MN-12, but MN-30 was still removing parts of its anterior axonal branch at 30\% PAT (Fig. 5) and traces of the recurrent branch of MN-1 were evident through at least $50 \%$ PAT. Thus, for these two neurons, parts of their axonal arbor continued to regress during the time that connected regions were starting their phase of active regrowth. In $\mathrm{MN}-12$, the regressing arbor appeared to be pinched off from the sprouting region by $15 \%$ PAT and, hence, could not be backfilled. Other techniques have revealed that remains of its larval arbor can still be found through the next $10-15 \%$ of adult differentiation (Truman, unpublished). 


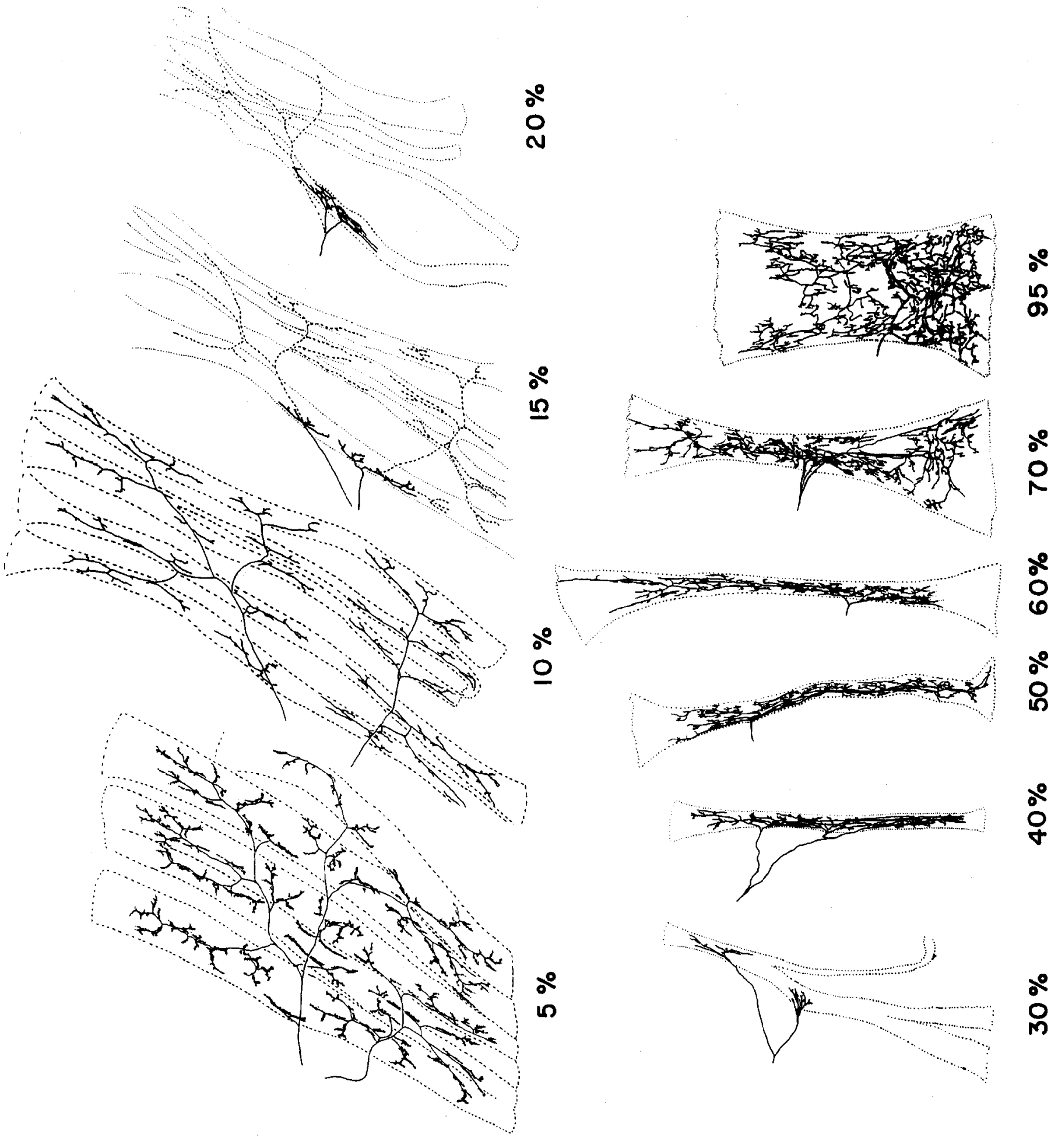


$P A T, 20-30 \%$. By $4 \mathrm{~d}$ after ecdysis, the anterior and posterior branches of $\mathrm{MN}-12$ showed obvious sprouts indicating the commencement of the adult outgrowth (Fig. 4; 20\%). These sprouts, though, remained localized to the middle and anterior regions of the anlage through the succeeding $2 \mathrm{~d}$ (Figs. 2-4; 30\%).

$P A T, 30-70 \%$. The period between 30 and $40 \%$ PAT was a time of rapid longitudinal growth of the axonal arbor. Of seven successful fills at $40 \%$ PAT, five showed arbors that had already reached the limits of the muscle anlage (e.g., Figs. 2, 4; 40\%).

Transverse "twigs" started to appear frequently along the longitudinal branches by 50\% PAT. These were typically short and irregularly shaped and were more evident on older (proximal) parts of the arbor. By $60 \%$ these "twigs" were present all along arbor (Fig. $3 ; 60 \%$ ) and, by $70 \%$ PAT, were splitting into small sprays of fine processes, each tipped by a nascent end plate (70\% PAT; Fig. 3; 70\%). At 70\% PAT we no longer found the short, irregularly shaped processes, suggesting that the generation of potential end plates was finished. We do not know if there is a subsequent period of end plate removal.

$P A T, 70-100 \%$. The remainder of adult development was devoted to the maturation of the adult end plates. Between 70 and $80 \%$ PAT the rapid expansion of the muscle fibers resulted in the passive separation of the members of a spray (Fig. 3; 80\%). During the last $20 \%$ of metamorphosis the end plates then grew substantially in size and acquired their adult shapes, which ranged from simple linear structures to ones with elaborately branched processes (Fig. 3; 90-100\%).

\section{The neuromuscular system in diapausing pupae}

Diapause is a statc of arrested devclopment maintaincd by the failure to secrete the ecdysteroids needed to promote adult differentiation. In diapausing pupae, the external muscles were regressed and noncontractile with no obvious distinction between regions that would regrow to form the adult muscles versus those that would not. For MN-12, the glia that ensheathed most of the axonal arbor were still present, although the only part of the arbor that could be backfilled was that at the site of future outgrowth (Fig. 6). Both MN-30 and MN-1 retained parts of their larval arbor that would be removed once adult differentiation resumed; these included the anterior branch of $\mathrm{MN}-30$ and the recurrent branch of $\mathrm{MN}-1$. Their partially regressed condition was stable and persisted until the secretion of ecdysteroids terminated diapause several months later.

\section{Effects of systemic treatment with juvenile hormone mimics (JHM) on neuromuscular reorganization}

Adult differentiation is caused by ecdysteroids acting in the absence of the JH. If JH is provided early in this ecdysteroid exposure, then differentiation is redirected into the pupal pathway rather than towards that of the adult. The extent of this redirection depends on the timing of the $\mathrm{JH}$ administration (Riddiford and Ajami, 1973). Groups of Manduca pupae were injected with $20 \mu \mathrm{g}$ of JHM at various times after pupal ecdysis and the formation of the neuromuscular system then assessed 2 to 3 weeks later at the end of adult development. With JHM treatment through the first $3 \mathrm{~d}$ after ecdysis, the resulting adults showed varying degrees of retention of pupal cuticle (see Riddiford and Ajami, 1973; Truman and Reiss, 1988). JHM treatments after 15-20\% PAT typically resulted in adult abdomens with normal morphology and pigmentation.

Effects on the muscle reorganization. None of the JHM treatments, which began at 5\% PAT, prevented the breakdown of the larval muscle fibers, but they had marked cffects on the subsequent formation of the adult neuromuscular system. Table 2 summarizes the effects of these treatments on the differentiation of the adult muscle DE5. This muscle was always composed of the small diameter fibers characteristic of the adult muscle, but its size, shape, and orientation varied with the time of JHM treatment. Early treatments resulted in the formation of DE5s having an aberrant shape; the muscle was broad in the middle to anterior region but narrowed markedly at its posterior attachment (Fig. 7). The widened region was duc to the presence of additional muscle fibers rather than to hypertrophy of individual fibers. To accommodate its unusual shape for size comparisons, we averaged measurements made in the broad and narrow regions of the muscle (see Materials and Methods). Animals treated with JHM at 5\% PAT produced muscles that were only $10-15 \%$ of the normal adult width (Table 2). Later treatments resulted in successively larger muscles until by $35-40 \%$ PAT the JHM treatment no longer blocked muscle growth and the animals formed muscles of normal size and shape. Up through about 25\% PAT the JHM treatment also blocked the reorientation of the muscle (Table 2).

An unexpected result of JHM treatment was the appearance of muscles that are normally absent in the adult. We commonly found muscles in the position of the larval DEO3 groups as "regrown" muscles in the adult. In the case of DEOl, fibers distal to fiber 1 often persisted to regrow and make a substantial contribution to the adult muscle. Also, for DIO, portions of the antcrior half of the muscle, which normally die, persisted to make adult muscle fibers. Therefore, the JHM treatment appears to block the removal of the "unneeded" remains of larval muscles, and these can then regrow to form adult muscles.

Effects on the axonal arbor and end plates. Treatment with JHM had profound effects on the remodeling of the axonal arbor of MN-12. After early treatment at 5-10\% PAT, the axonal arbor was subsequently pruned back but regrowth did not occur. In the adult, the two branches of the axon were still at their initial sitcs of contact with sprouts that showed some swellings but without organized structures that resembled either larval or adult end plates (Figs. 7, 8A). The widest portion of the muscle was invariably the region in contact with the motoneuron.

Animals treated at $15 \%$ PAT showed moderate regrowth of their axonal arbor, but again, it was largely confined to the zone of original contact with MN-12 (Fig. 7, Table 2). The fine axonal branches ended in end plates that had a beaded appearance with severe constrictions (Fig. 8B), a feature that is seen in neither larval nor adult end plates.

Treatment between 20 and 30\% PAT was followed by the formation of adult end plates having a normal morphology (Fig. $8 C$ ). The axonal arbor formed by $\mathrm{MN}-12$ was more extensive

$\leftarrow$

Figure 2. Camera lucida drawings of cobalt-filled processes showing the change in the axonal arbor of MN-12 as its larval target (DEOI) degenerates and then regrows to become an adult muscle (DE5). Numbers refer to the \% PAT. The heavy dashed lines at $15 \%$ and $20 \%$ show the glial sheath that extends beyond the portion of the axon that can be filled. In the first three examples, the initial branch point of the axon is well proximal to the muscle and not drawn. 

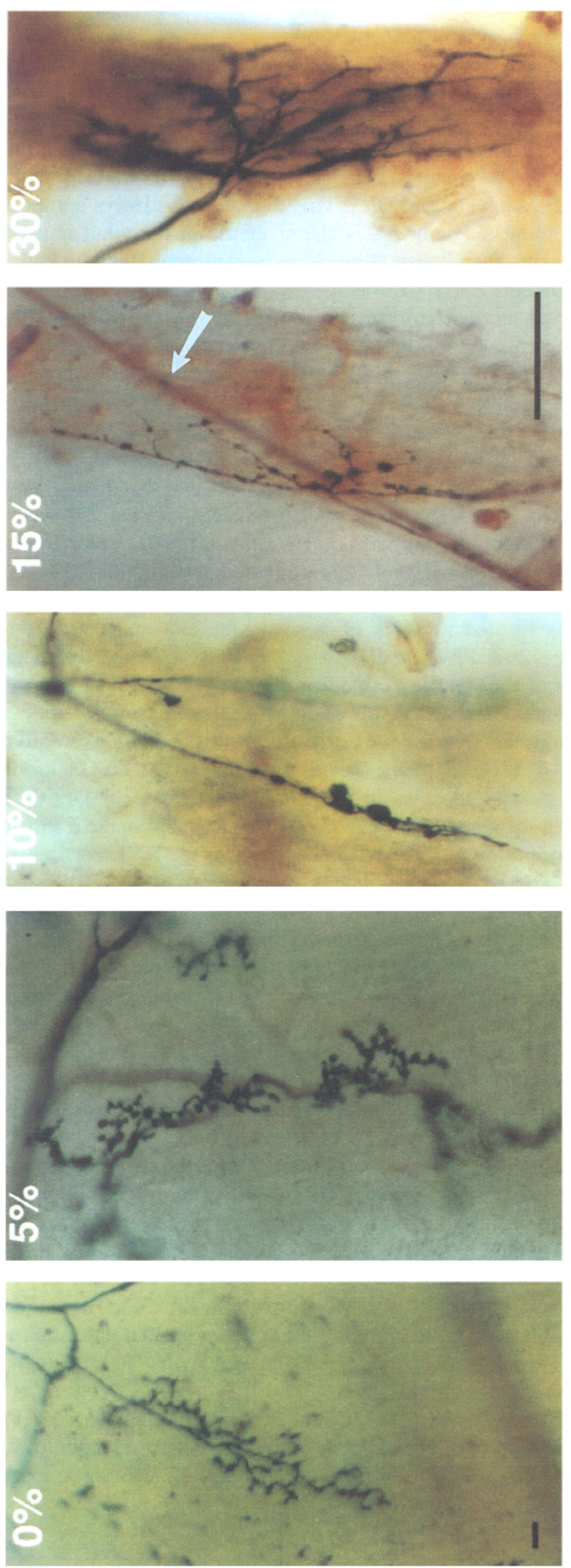
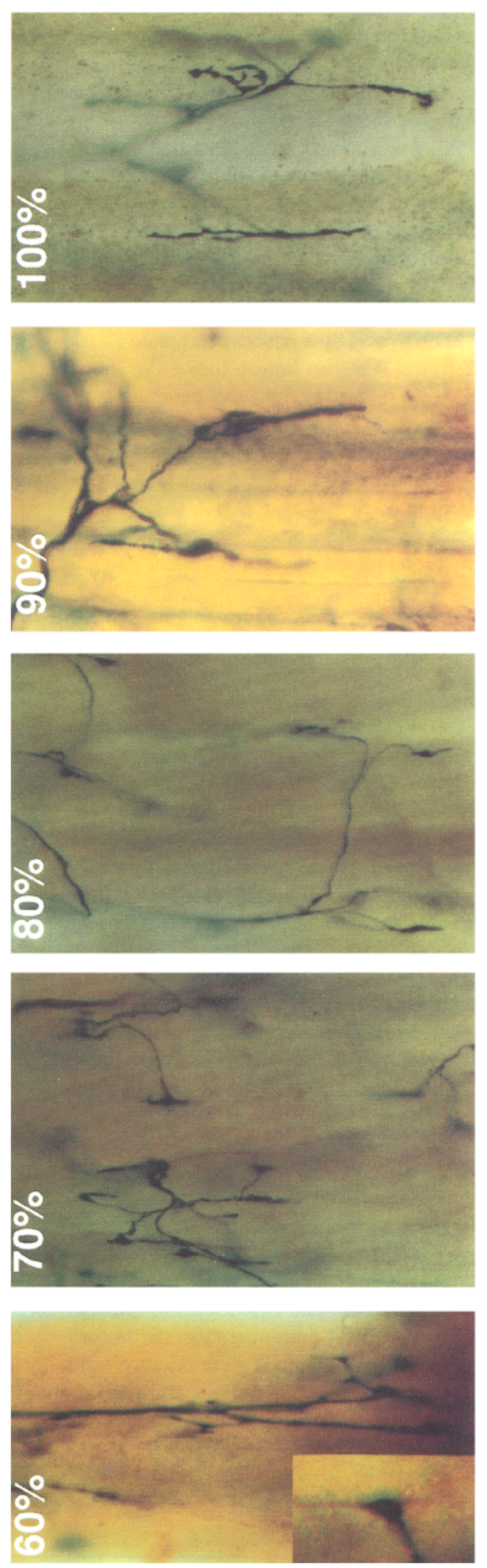

$\therefore 0$ 을

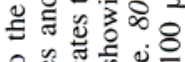
8 월

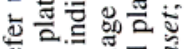
这记

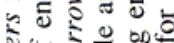
จำ

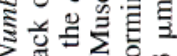

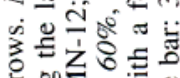

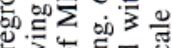

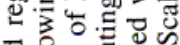

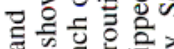
制 는 w

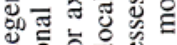

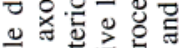

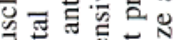
要语

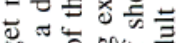

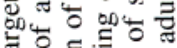
으을 3 5 年

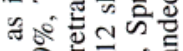
논ㅎํ웛 之况只

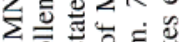

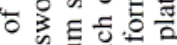

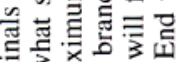

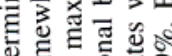

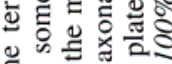
bo 000 을 虽

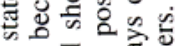
느을 on 要

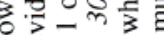

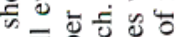

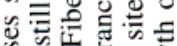

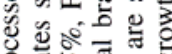

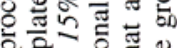
婙

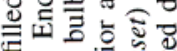

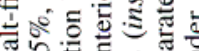
员记

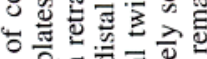
证

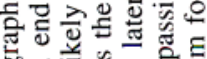

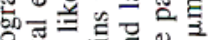

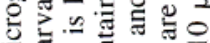
ह 해웡

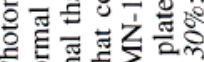

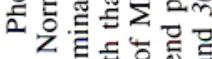

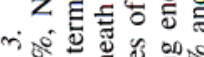
읭

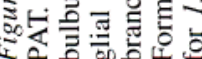




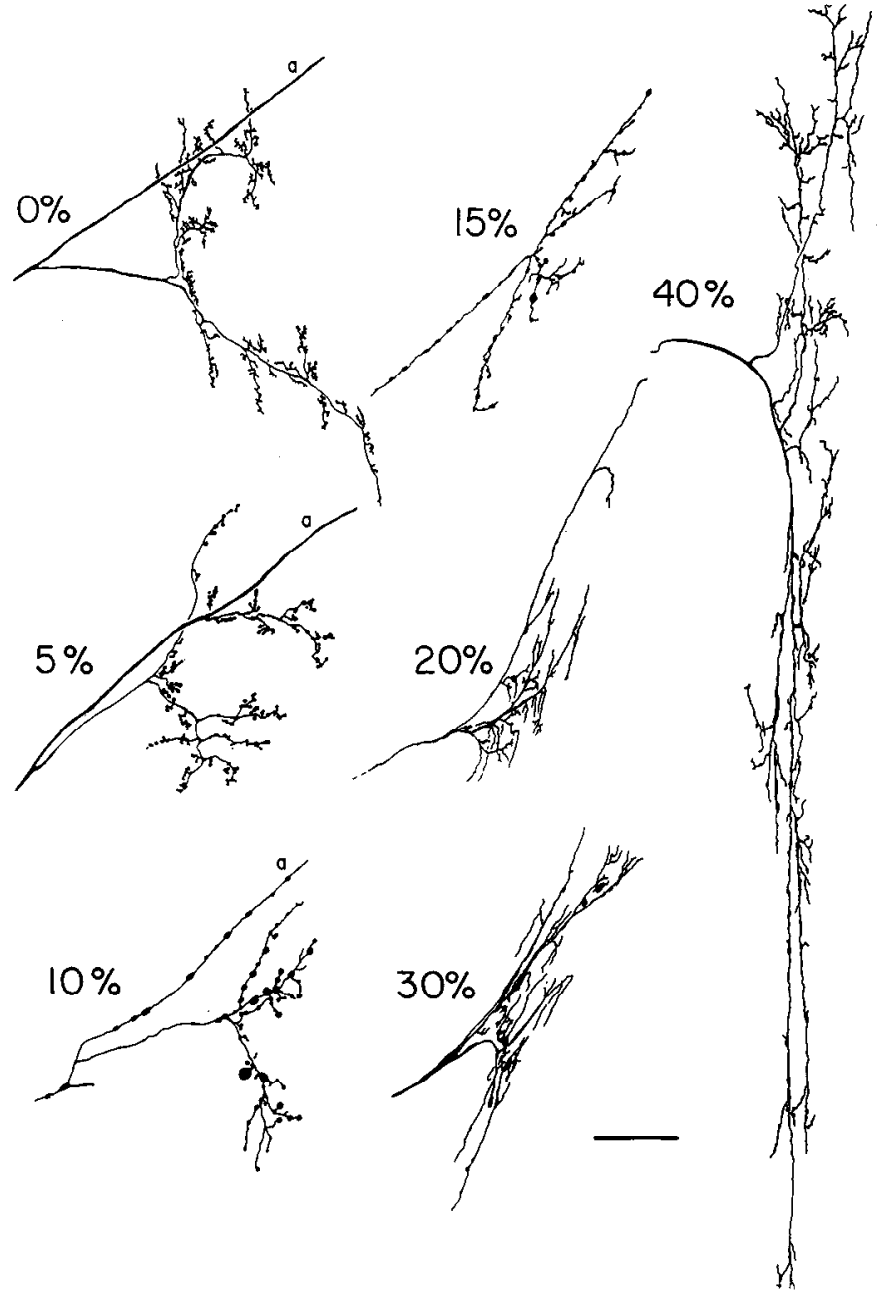

Figure 4. Camera lucida drawings of cobalt-filled processes of MN12 showing the changes that occur at the first contact of MN-12's anterior axon branch with fiber 1 of its target muscle. The distal portions of the anterior axon $(a)$ are retracted between $10 \%$ and 15\% PAT. Scale bar, $100 \mu \mathrm{m}$.

than that seen after treatment at 15\% PAT (Fig. 7) but it was still confined to a transverse band on the muscle (Table 2).

$\mathrm{MN}-12$ starts rapid longitudinal growth over its target after $30 \%$ PAT (Fig. 2). JHM treatment after this time did not block this growth, and the neuron subsequently produced an arbor that extended over most of the length of the muscle (Table 2).

\section{Topical application of $J H M$}

To determine which effects of JHM treatment were due to actions on the motoneurons and which to actions on their muscles, we topically applied JHM to the surface of a dorsal hemisegment (see Materials and Methods). The other side of the segment served as the control. In this way, selected muscles were exposed to JHM during the time that ecdysteroids were causing differentiation but the cell bodies of their motoneurons experienced ecdysteroids alone. About $40 \%$ (18 of 46$)$ of the animals showed retardation of muscle growth on the control as well as the treated side, suggesting significant leakage of hormone into the circulation. These were not considered further. The remaining animals showed normal growth of muscles on the control side but severely retarded growth on the treated side. Even in

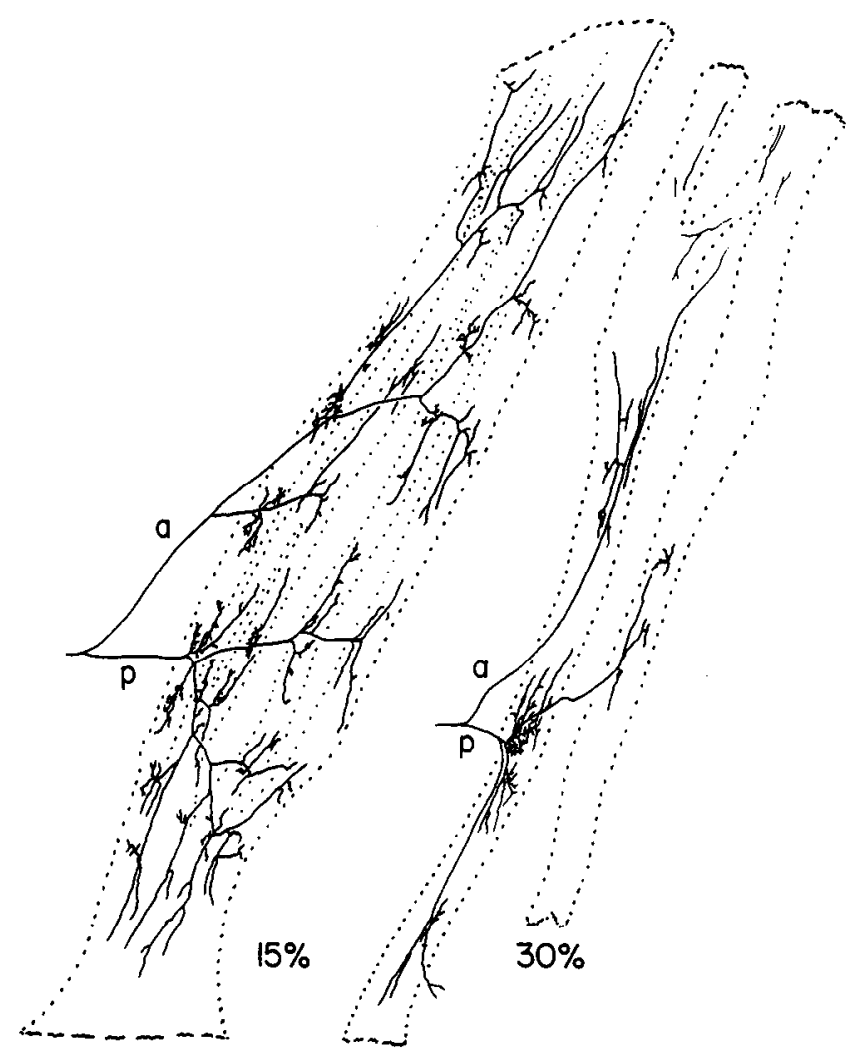

Figure 5. Camera lucida drawings of cobalt-filled MN-30 showing the morphology of its axonal arbor at $15 \%$ and $30 \%$ PAT. In the latter case, the anterior axon $(a)$ is still undergoing degeneration as the posterior axon $(p)$ is showing adult sprouting.

these animals, though, there was some suppression of the muscle reorientation.

As seen in Table 3, the effects of topical JHM treatment on average muscle growth and orientation was similar to that seen after systemic treatment with the mimic. The muscles, though were of uniform diameter rather than being bottle shaped (compare Figs. 7, 9). The topical treatment also resulted in the retention of ectopic muscles such as the anterior portions of DIO (Fig. 10), a feature also seen after JHM injection.

We were especially interested in the growth of the adult motoneurons that were faced with these juvenilized targets. MN-12 showed extensive longitudinal growth over its juvenilized target (Table 3, Fig. 9) rather than the restricted growth seen when both neuron and muscle were exposed to JHM (Fig. 7). The response of $\mathrm{MN}-30$ was especially interesting because this neuron undergoes sprouting and arbor removal simultaneously. We filled the arbor of MN-30 in 13 individuals that were topically treated at $15 \%$ or $20 \%$ PAT. The anterior axon branch was preserved in all instances. By contrast, the MN-30s innervating the contralateral (untreated) DE3s showed the normal loss of this branch (Fig. 10). As seen with MN-12, the growth of MN-30 was more extensive in topically treated animals versus those that were systemically treated $(n=16)$, despite the fact that in both cases the neurons were growing over juvenilized targets of similar size. In 6 of the 13 cells, the neuron produced excess arbor that appeared as tangles of processes (Fig. 10), or as isolated or collected bundles of processes extending well off of the target muscle. Similar signs of overgrowth were not evident in any of 16 successfully filled $\mathrm{MN}-30$ s from animals that were systemi- 


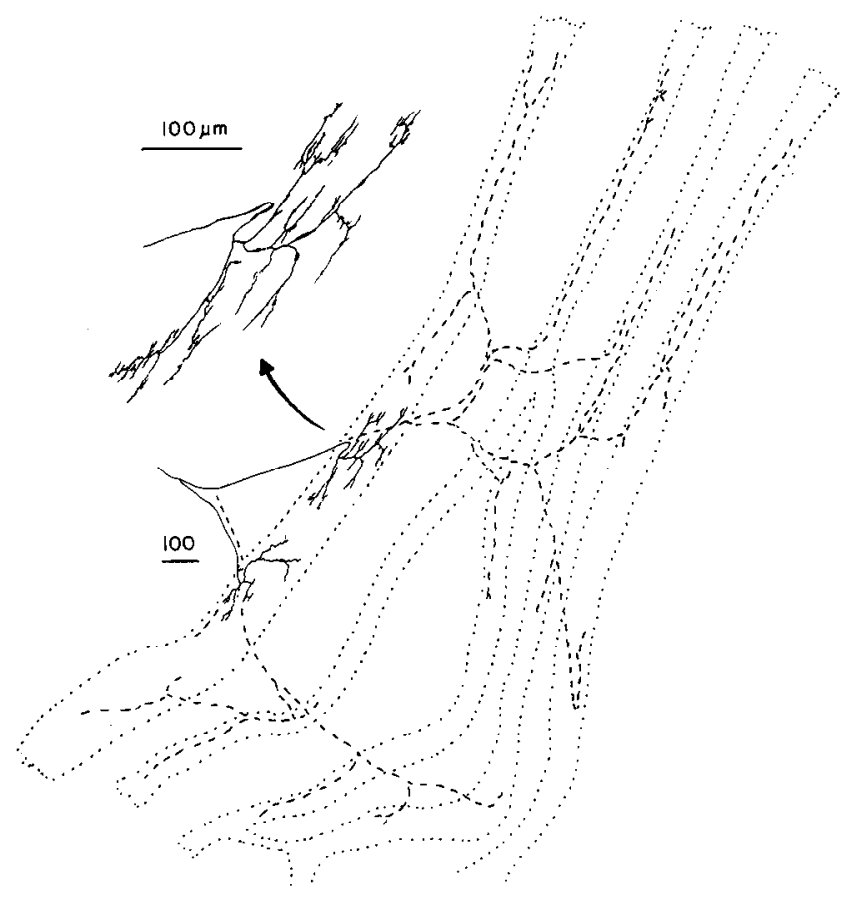

Figure 6. Camera lucida drawings of cobalt-filled MN-12 showing the morphology of its axonal arbor during pupal diapause. Inset shows a magnification of the anterior contact site. Dashed lines show the location of the persisting sheath glial cells; dotted lines give the outline of the degenerate muscle fibers.

cally treated at 15 to $25 \%$ PAT (data not shown). Although these topically treated animals were exuberant in their production of processes, they formed only moderate numbers of end plates.

\section{Discussion}

\section{Time course of neuromuscular reorganization}

The studies by Nüesch and his students (reviewed in Nüesch, 1985) on the metamorphosis of the flight musculature of moths showed that the adult muscles are built from the remains of the larval fibers. Higher flies like Drosophila deviate from this pattern in that many of the adult muscles form de novo (Currie and Bate, 1991), but the abdominal muscles Manduca conform with Nüesch's observations. Of the motor units considered, MN-12/ DEO1 showed the best separation between the phases of regression and regrowth (Fig. 11). The first $15 \%$ of the pupal adult transition is devoted to the loss of larval structures-the muscle loses contractility and the larval motor end plates are lost between 5 and $10 \%$ PAT. During the next $5 \%$ most of the terminal axonal arbor then disappears. Beyond 15\% PAT activities of MN-12 are devoted to the growth of its adult arbor. MN-1 and $\mathrm{MN}-30$ showed target degeneration and end plate loss according to the same schedule as seen for MN-12. Both neurons, though, eventually lost a major axon branch, and the removal of this branch overlapped into the period of axonal sprouting.

Adult growth is evident in all cells by $20 \%$ PAT. For MN-12, axonal sprouts appeared between 15-20\% PAT but stayed in a localized region of the anlage through the next $10 \%$. The subsequent growth of the arbor can be divided into two discrete phases. Major longitudinal branches were established between 30 and $45 \%$ PAT. This phase of longitudinal growth then blended into a second phase that emphasized production of short transverse processes (45-60\% PAT) which subdivided to form
Table 2. Effects of the timing of systemic treatment with JHM on the subsequent growth and orientation of muscle DE5 and the longitudinal spread of the axonal arbor of $\mathrm{MN}-12$ over the muscle

\begin{tabular}{|c|c|c|c|c|c|}
\hline \multirow[b]{2}{*}{$\begin{array}{l}\text { Time of } \\
\text { treatment } \\
\left(\% \mathrm{PAT}^{a}\right)\end{array}$} & \multicolumn{3}{|c|}{ Muscle parameters } & \multicolumn{2}{|c|}{$\begin{array}{l}\text { Motoneuron } \\
\text { arbor }\end{array}$} \\
\hline & $N$ & $\begin{array}{l}\text { Width }^{b} \\
(\mathrm{~mm} \pm \mathrm{SD})\end{array}$ & $\begin{array}{l}\text { Insertion } \\
\text { angle } \\
\text { (degrees } \\
\pm \text { SD) } \\
\end{array}$ & $N$ & $\begin{array}{l}\text { Longi- } \\
\text { tudinal } \\
\text { extent } \\
(\% \pm S D)\end{array}$ \\
\hline $5 \%$ & 7 & $0.12 \pm 0.02$ & $58 \pm 8$ & 3 & $30 \pm 9$ \\
\hline $10 \%$ & 13 & $0.18 \pm 0.03$ & $53 \pm 6$ & 8 & $31 \pm 8$ \\
\hline $15 \%$ & 7 & $0.18 \pm 0.03$ & $58 \pm 8$ & 4 & $37 \pm 9$ \\
\hline $20 \%$ & 16 & $0.23 \pm 0.04$ & $55 \pm 11$ & 10 & $36 \pm 6$ \\
\hline $25 \%$ & 12 & $0.27 \pm 0.07$ & $65 \pm 10$ & 8 & $41 \pm 12$ \\
\hline $30 \%$ & 4 & $0.34 \pm 0.07$ & $83 \pm 11$ & 3 & $41 \pm 15$ \\
\hline $35 \%$ & 4 & $0.73 \pm 0.21$ & $89 \pm 2$ & 3 & $81 \pm 7$ \\
\hline $40 \%$ & 4 & $0.75 \pm 0.05$ & $89 \pm 5$ & & no data \\
\hline No treatment & 5 & $0.98 \pm 0.07$ & $85 \pm 11$ & 5 & $82 \pm 4$ \\
\hline
\end{tabular}

Measurements were performed after the completion of the pupal-adult transformation.

a Percentage of the pupal-adult transformation.

${ }^{b}$ The muscle width was measured $25 \%$ of the distance from the origin and $25 \%$ from the insertion. The average of the two measurements was then used. - Calculated as the length of the muscle that is covered by innervation divided by the total length of the muscle.

sprays of end plates (by $70 \%$ PAT). This latter process was finishing as the muscle anlage was splitting into birefringent fibers. The nascent end plates then became laterally separated due to the rapid growth of the muscle fibers. They finished their growth and morphological maturation during the last $30 \%$ of metamorphosis. The latter association of end plate growth with that of its muscle is similar to that seen for androgen-sensitive muscles in the rat (Balice-Gordon et al., 1990).

\section{Control of the regression of the larval neuromuscular system}

The first 15\% PAT involves involution of larval muscles and removal of larval end plates and axonal arbors. Studies on larval proleg muscles showed that muscle regression is induced by the prepupal ecdysteroid peak that causes pupation (Randall, 1970; Weeks and Truman, 1985; Weeks, 1987). Similar experiments also implicate the prepupal peak in the degeneration of the dorsal external muscles (Wright and Truman, 1994), even though the latter is delayed until after pupal ecdysis. The muscle remains then persist, even through the months of pupal diapause, until ecdysteroids (Warren and Gilbert, 1986) cause them to either die or regrow during adult differentiation.

The mechanism underlying the loss of the larval end plates is not known. Ultrastructural studies of end plate loss from the thoracic muscles in Manduca reveal changes in the surrounding glia that precede neuronal or muscle alterations (Rheuben, 1992). The relatively simultaneous disruption of end plates around 5\% PAT suggests that the end plates are responding to a wide-spread signal but the nature and targets of this signal are unknown.

The subsequent pruning back of axonal arbor likely involves signals from the target. For neurons with large arbors such as $\mathrm{MN}-1$ and $\mathrm{MN}-30$, one axon branch may be regressing while the other is actively sprouting (e.g., Fig. 5). These differences may reflect variation in the ability of the axon branches to respond to trophic factors that sustain growth. Alternatively, dif- 


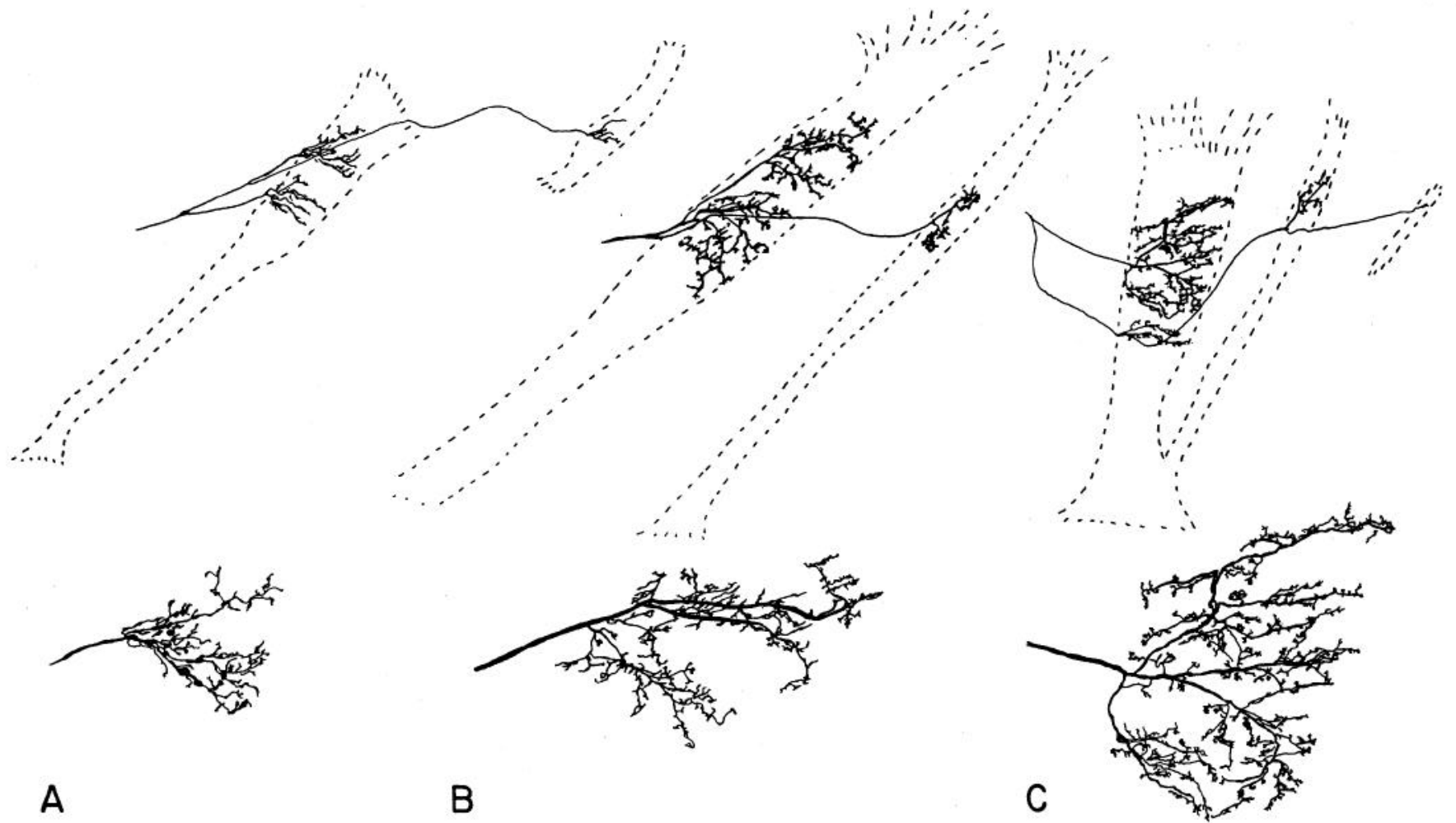

Figure 7. Camera lucida drawings of cobalt-filled MN-12s showing the effects of systemic treatment with a juvenile hormone mimic on the subsequent growth and differentiation of the motoneuron and its target. Pupae were treated at $(A)$ 5\% PAT, $(B)$ 15\% PAT, and $(C)$ 25\% PAT and subsequently examined after the completion of adult differentiation. All had a regrown fiber 1 plus the remains of at least the second fiber. Inset shows a magnification of the entire adult arbor that formed from the anterior contact site.

ferent regions of the degenerating target may vary in their ability to support axonal sprouting (e.g., Purves, 1986; Campenot, 1994). Lacking this target support, growth of a particular branch could not be maintained and the branch would regress.

An involvement of the target in directing the axonal pruning is suggested by the results of topical treatment with JHM. Ectopic muscles were regrown and these, in turn, were associated with nerve branches that should have been lost (Fig. 10). We do not think that the motoneurons were responding directly to the JHM applied to their target since the treatment did not interfere with the neurons' sprouting responses. We suggest that JHM acts directly on the muscle fibers to prevent their final removal. Their presence and altered state may then support the maintenance of axon branches, which can then persist and sprout through metamorphosis.

The androgen-dependent elimination of synapses from the levator ani muscle in rats is an example of hormone-induced synapse elimination in mammals (Jordan et al., 1989). In this case, the period of synapse elimination coincides with the appearance of androgen binding by motoneurons in the corresponding spinal nucleus (Jordan et al., 1991). This coincidence suggests that androgens my act directly on the motoneurons to influence synapse
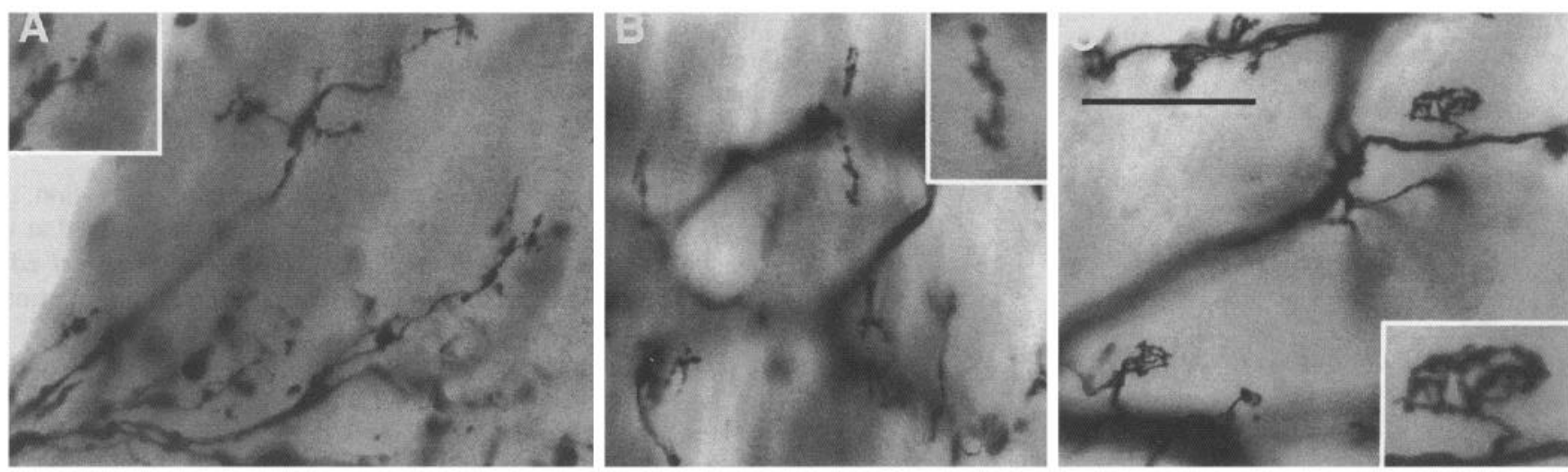

Figure 8. Photomicrographs of cobalt-filled processes of MN-12 showing the state of the terminals that form after animals had been treated with a juvenile hormone mimic at $(A) 5 \%$ PAT, $(B)$ 15\% PAT or $(C)$ 25\% PAT. These are from the same specimens depicted in Figure 7 . Insets show magnified views of the end plates. Scale bar, $50 \mu \mathrm{m}(25 \mu \mathrm{m}$ for insets $)$. 
Table 3. Effects of topical treatment with JHM on the subsequent growth and orientation of muscle DE5 underlying the site of application and the Iongitudinal spread of the axonal arbor of $\mathrm{MN}-12$ over that muscle

\begin{tabular}{|c|c|c|c|c|c|}
\hline \multirow{2}{*}{$\begin{array}{l}\text { Time } \\
\text { of } \\
\text { treat- } \\
\text { ment } \\
(\% \\
\text { P } \% \text { T }) \\
\end{array}$} & \multicolumn{3}{|c|}{ Muscle parameters } & \multicolumn{2}{|c|}{$\begin{array}{l}\text { Motoneuron } \\
\text { arbor }\end{array}$} \\
\hline & $N$ & $\begin{array}{l}\text { Width }^{a} \\
(\mathrm{~mm} \pm \mathrm{SD})\end{array}$ & $\begin{array}{l}\text { Insertion } \\
\text { angle } \\
\text { (degrees } \\
\pm \text { SD) }\end{array}$ & $N$ & $\begin{array}{l}\text { Longi- } \\
\text { tudinal } \\
\text { extent } \\
(\% \pm S D)\end{array}$ \\
\hline $10 \%$ & 4 & $0.16 \pm 0.04$ & $65 \pm 4$ & 4 & $77 \pm 13$ \\
\hline $15 \%$ & 9 & $0.24 \pm 0.08$ & $61 \perp 8$ & 9 & $73 \pm 12$ \\
\hline $20 \%$ & 5 & $0.24 \pm 0.09$ & $70 \pm 8$ & 5 & $78 \pm 14$ \\
\hline
\end{tabular}

Measurements were performed after the completion of the pupal-adult transformation.

"The muscle width was measured $25 \%$ of the distance from the origin and $25 \%$ from the insertion. The average of the two measurements was then used. ${ }^{b}$ Calculated as the length of the muscle that is covered by innervation divided by the total length of the muscle.

elimination. It does not, though, exclude an action also working through the muscle.

\section{Control of the growth of the adult neuromuscular system}

Innervation is required for muscle growth during metamorphosis (Nüesch, 1985; Thorn and Truman, 1989; Wright and Truman, 1994). This trophic relationship apparently underlies the abnormal shape of the DE5s that form after systemic treatment with JHM (Fig. 7). In the latter case, the juvenilized neuron fails to show longitudinal spread and muscle growth is limited to the zone of neuronal contact. Interestingly, in animals topically treated with JHM, MN-12 undergoes its normal spread and, accordingly, muscle growth is uniform along its length (Fig. 9), albeit at a reduced level from that seen in untreated animals. This complex interplay of hormones and innervation on muscle development is seen in other systems such as the development of the laryngeal muscle in adult Xenopus (Tobias et al., 1993).

The muscle anlagen also reorients during metamorphosis. A

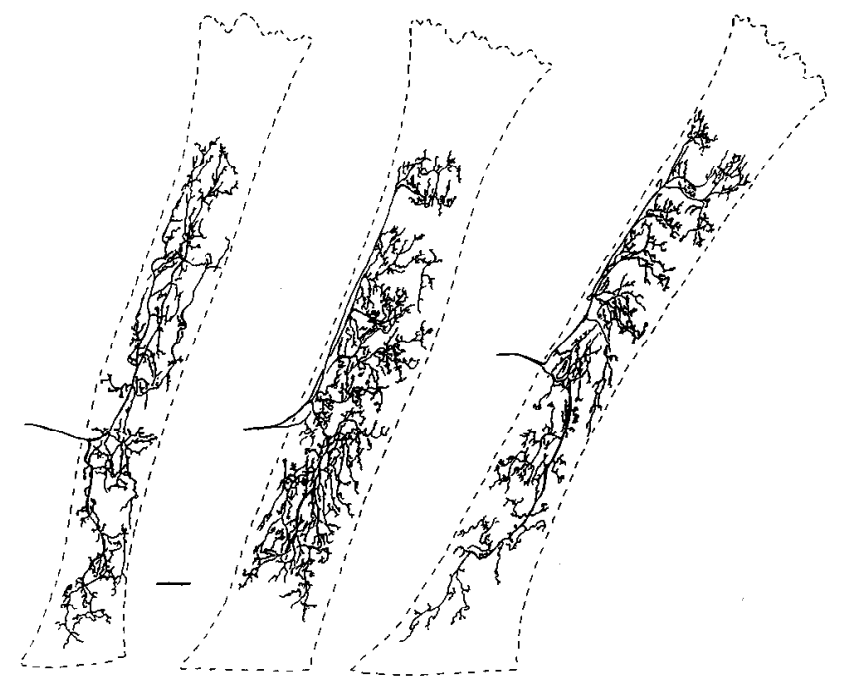

Figure 9. Camera lucida drawings of three examples of cobalt-filled MN-12 showing the morphology of its axonal arbor and target muscle after the completion of adult development. The devcloping pupac were treated topically with the JH mimic at $15 \%$ PAT and the muscle underlying the site of application is shown. Scale bar, $100 \mu \mathrm{m}$.

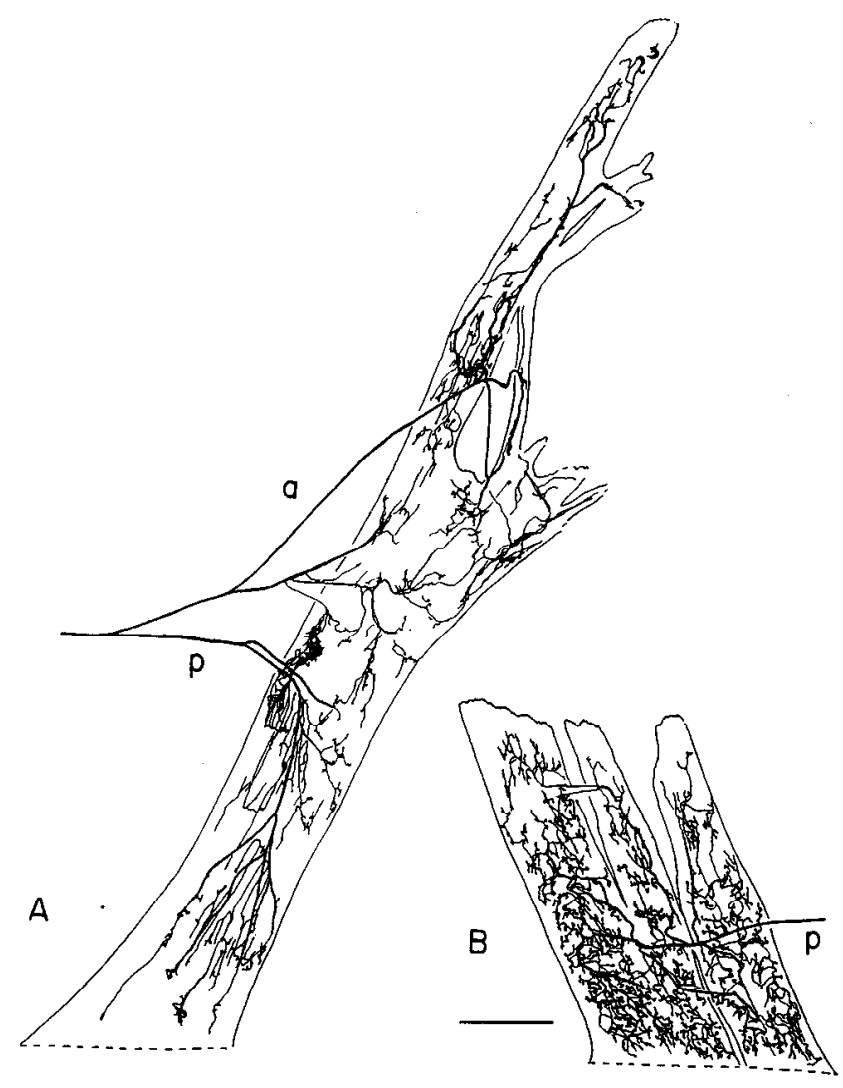

Figure 10. Camera lucida drawings of the axonal arbors of motoneuron MN-30 over muscle DE3 after topical treatment with JHM at $15 \%$ PAT and then examination in the adult. $A$, Muscle and arbor from a treated side. $B$, Muscle and arbor from the control side of a treated segment. The two drawings are not from the same individual. The muscles on the control side of $A$ showed full adult growth, but the cobalt fill was unsuccessful; the treated side of $B$ showed preservation of ectopic muscle similar to $A$, but the fill was incomplete. Note in $A$ the preservation of the anterior axonal branch $(a)$ and areas of tangled processes near the posterior $(p)$ branch. Scale bar, $0.5 \mathrm{~mm}$.

series of grafting experiments in the beetle Tenebrio showed that the muscle reorientation occurs by the active migration of the anlage over the epidermal pavement (Williams and Caveny, 1980 a,b). Our obscrvations support this migration hypothesis. JHM given after $15 \%$ PAT has no effect on the normal patterning of the abdominal epidermis. Normally, DE5 attaches to a site underlying a large spot of orange scales lateral to the midline. In JHM-treated animals, the anterior attachment of DE5 remains at its old larval position which is medial to the orange spot. Hence, the JHM treatment appears capable of blocking the migration of the anlage up until the time that the migration actually begins at $35 \%$ PAT (Table 2).

Although the growth of the muscle requires innervation, the reorientation of the anlage does not. Muscles denervated at the start of the pupal stage, nevertheless, assume their proper adult orientation, although they do not grow (Thorn and Truman, 1989; Truman, unpublished).

Hormone-induced sprouting appears to be mediated through actions on the cell body. For example, the sprouting of axonal terminals of the gin-trap afferents during pupation in Manduca depends on the hormonal environment of the cell body and not of the terminals (Levine et al., 1986; Levine 1990). Similar results are seen for the thyroxine-induced sprouting of ganglion cells in Xenopus (Hoskins and Grobstein, 1985). The ability of 

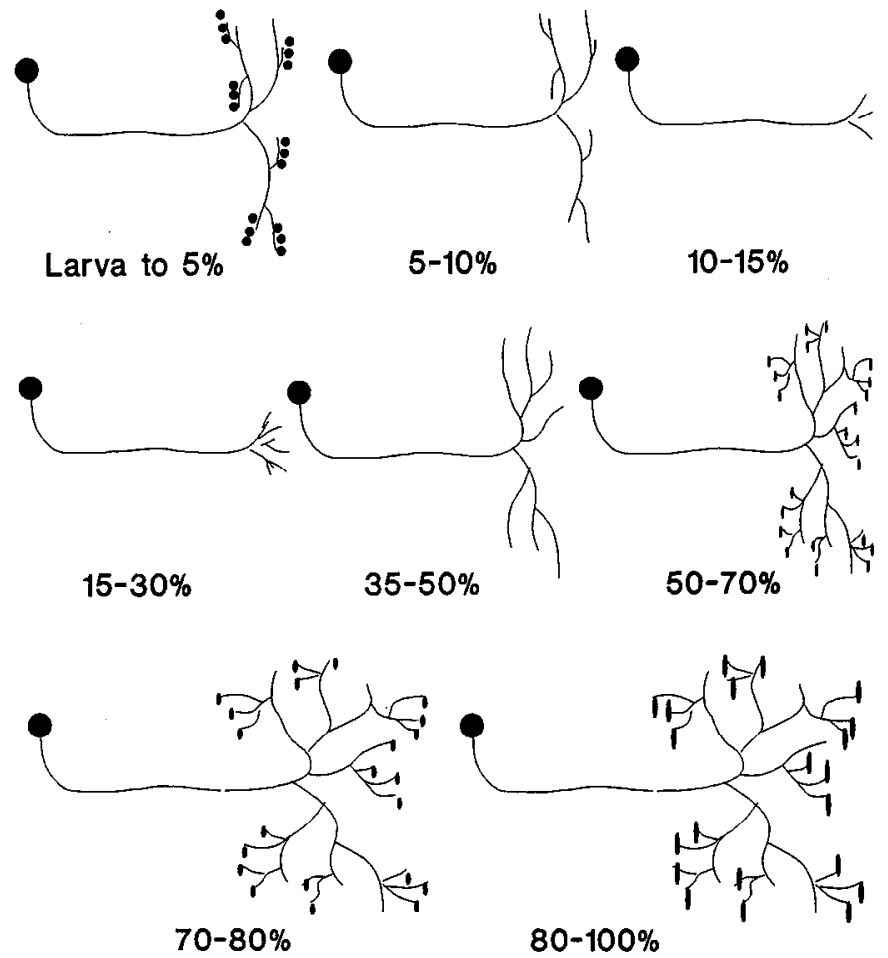

Figure 11. Summary of the time course of changes that occur in larval motoneuron MN-12 during its metamorphosis into the adult cell. See Discussion for details.

Manduca motoneurons to regulate dendritic sprouting in response to ecdysteroids and $\mathrm{JH}$ has been elegantly shown for isolated leg motoneurons that are maintained in vitro (Prugh et al., 1992).

One phase of axonal sprouting by Manduca motoneurons also seems to depend on the hormonal environment of their cell bodies. Systemic treatment with JHM suppresses both the axonal sprouting and the regrowth of target muscles. By contrast, local treatment with JHM suppresses target growth but not axonal sprouting. Hence, for $\mathrm{MN}-12$, its initiation of the phase of longitudinal growth requires that its cell body sees ecdysteroids without $\mathrm{JH}$; the presence of $\mathrm{JHM}$ in the periphery appears to be irrelevant.

The importance of the environment of the cell body for sprouting is further supported by observations on MN-30. With systemic JHM treatments, the amount of axonal regrowth was reduced to match the reduced size of the target (data not shown). With topical treatments, by contrast, the neuron showed excessive growth over the target, occasionally resulting in abnormal collections of arbor (Fig. 10). Presumably, the latter condition results from confronting a cell with a normal program of growth (due to exposure of its cell body to ecdysteroids) with a target that is too small for this growth.

An interesting aspect of systemic treatment with JHM after 20-25\% PAT is that it blocked the early phase of longitudinal growth but not the later phase associated with end plate formation. We have not yet made counts of the numbers of end plates formed after the various JHM treatments and how these relate to the number of muscle fibers that are formed. It is clear, though, that the total number of end plates is greatly reduced in the JHM-treated animals that form small muscles as compared with that seen for normal DE5s. Importantly, this reduction in end plates is also seen in topically treated animals, despite their excessive production of processes. Therefore, unlike its longitudinal sprouting, the end plate formation by $\mathrm{MN}-12$ seems to depend on the state of the target. Since we only examined animals after the completion of metamorphosis, this adjustment could arise through regulation of end plate formation and/or the subsequent removal of excess end plates. We think it likely that at least part of the control is exerted during the formation of transverse sprouts at $40-70 \%$ PAT as the muscle anlagen is dividing into muscle fibers.

Thus, the two phases of the axonal sprouting may be controlled by ecdysteroids via different pathways. The rapid longitudinal growth of the axon over its target likely results from ecdysteroids acting directly on the cell body. By contrast, the subsequent production and maintenance of transverse sprouts that form the end plates may depend on target size; the latter heing a function of hoth innervation and hormone exposure. Thus, the neuromuscular system in Manduca appears to provide an in vivo system in which to study the complex factors that regulate neuronal shape and connectivity.

\section{References}

Bacon JP, Altman JS (1977) A silver intensification method for cobaltfilled neurones in whole mount preparations. Brain Res 138:359-363.

Balice-Gordon RJ, Breedlove SM, Bernstein S, Lichtman JW (1990) Neuromuscular junctions shrink and expand as muscle fiber size is manipulated: in vivo observations in the androgen-sensitive bulbocavernosus muscle of mice. J Neurosci 10:2660-2671.

Bell RA, Joachim FA (1976) Techniques for rearing laboratory colonies of tobacco hornworms and pink bollworms. Ann Entomol Soc Am 69:365-373.

Campenot RB (1994) NGF and the local control of nerve terminal growth. J Neurobiol 25:599-611.

Currie D, Bate M (1991) Development of adult abdominal muscles in Drosophila: adult myoblasts express twist and are associated with nerves. Development 113:91-102.

Heinertz R (1976) Untersuchungen am thorakalen Nervensystem von Antheraea polyphemus $\mathrm{Cr}$. (Lepidoptera) unter besonderer Berücksichtigung der Metamorphose. Rev Suisse Zool 83:215-242.

Hoskins SG, Grobstein P (1985) Development of the ipsilateral retinothalamic projection in the frog Xenopus laevis. III. The role of thyroxine. J Neurosci 5:930-940.

Jacobs GA, Weeks JC (1990) Postsynaptic changes at a sensory-tomotor neuron synapse contribute to the developmental loss of a reflex behavior during insect metamorphosis. J Neurosci 10:1341-1356.

Jordan CL, Letinsky MS, Arnold AP (1989) The role of gonadal hormones in neuromuscular synapse elimination in rats. I. Androgen delays the loss of multiple innervation in the Levator Ani muscle. $\mathbf{J}$ Neurosci 9:229-238.

Jordan CL, Breedlove SM, Arnold AP (1991) Ontogeny of steroid accumulation in spinal lumbar motoneurons of the rat: implications for androgen's site of action during synapse elimination. J Comp Neurol 313:441-448.

Kent KS, Levine RB (1988) Neural control of leg movements in a metamorphic insect: persistence of the larval leg motor neurons to innervate the adult legs of Manduca sexta. J Comp Neurol 276:3043.

Lazar G (1978) Application of cobalt filling technique to show retinal projections in a frog. Neuroscience 3:725-736.

Levine RB (1990) Expansion of the central arborizations of persistent sensory neurons during insect metamorphosis: the role of the steroid hormone, 20-hydroxyecdysone. J Neurosci 9:1045-1054.

Levine RB, Truman JW (1985) Dendritic reorganization of abdominal motoneurons during metamorphosis of the moth, Manduca sexta. $\mathrm{J}$ Neurosci 5:2424-2431.

Levine RB, Pak C, Linn D (1985) The structure, function and metamorphic reorganization of somatotopically projecting sensory neurons in Manduca sexta larvae. J Comp Physiol 157:1-13.

Levine RB, Truman JW, Linn D, Bate CM (1986) Endocrine regulation of the form and function of axonal arbors during insect metamorphosis. J Neurosci 6:293-299. 
Levine RB, Fahrbach SE, Weeks JC (1991) Steroid hormones and the reorganization of the nervous system during insect metamorphosis. Semin Neurosci 3:437-447.

Nüesch H (1985) Control of muscle development. In: Comprehensive insect physiology, biochemistry and pharmacology, Vol 2 (Kurkut GA, Gilbert LI, eds), pp 425-452. Oxford: Pergamon.

Prugh J, Della Croce K, Levine RB (1992) Effects of the steroid hormone, 20-hydroxyecdysone, on the growth of neurites by identified insect motoneurons in vitro. Dev Biol 154:331-347.

Purves D (1986) The trophic theory of neural connections. Trends Neurosci 9:486-489.

Randall WC (1970) Ultrastructural changes in the proleg retractor muscles of Galleria mellonella after denervation. J Insect Physiol 16: 1927-1943.

Rheuben MB (1992) Degenerative changes in the structure of neuromuscular junctions of Manduca sexta during metamorphosis. J Exp Biol 167:119-154.

Rheuben M, Kammer AE (1980) Comparison of slow larval and fast adult muscles innervated by the same motor neurone. J Exp Biol 84: $103-118$.

Riddiford LM, Ajami AM (1973) Juvenile hormone: its assay and effects on pupae of Manduca sexta. J Insect Physiol 19:749-762.

Riley DA (1977) Spontaneous elimination of nerve terminals from the endplates of developing skeletal myofibers. Brain Res 134:279-285.

Riley DA (1981) Ultrastructural evidence for axon retraction during the spontaneous elimination of polyneuronal innervation of the rat solcus musclc. J Ncurocytol 10:425-440.

Sandstrom DJ, Weeks JC(1991) Reidentification of larval interneurons in the pupal stage of the tobacco hornworm, Manduca sexta. J Comp Neurol 308:311-327.

Schwartz LM, Truman JW (1983) Hormonal control of rates of metamorphic development in the tobacco hornworm Manduca sexta. Dev Biol 99:103-114.

Sonea IM, Rheuben MB (1992) Degenerative changes in the function of neuromuscular junctions of Manduca sexta during metamorphosis. J Exp Biol 167:61-89.

Taylor HM, Truman JW (1974) Metamorphosis of the abdominal ganglia of the tobacco hornworm, Manduca sexta: changes in populations of identified motor neurons. J Comp Physiol 90:367-388.

Thorn RS, Truman JW (1989) Neuronal respecification during the metamorphosis of the genital segments in the tobacco hornworm moth, Manduca sexta. J Comp Neurol 284:489-503.

Thorn RS, Truman JW (1994) Sexual differentiation in the CNS of the moth, Manduca sexta. II. Target dependence for the survival of the imaginal midline neurons. J Neurobiol 25:1054-1066.

Tobias ML, Marin ML, Kelley DB (1993) The roles of sex, innervation, and androgen in laryngeal muscle of Xenopus laevis. J Neurosci 13:324-333.

Truman JW (1988) Hormonal approaches to the study of nervous system development in insects. Adv Insect Physiol 21:1-34.

Truman JW, Reiss SE (1976) Dendritic reorganization of an identified motoneuron during metamorphosis of the tobacco hornworm moth. Science 192:477-479.

Truman JW, Reiss SE (1988) Hormonal regulation of the shape of identified motoneurons in the moth, Manduca sexta. J Neurosci $8: 765-775$.

Waldrop B, Levine RB (1992) Intersegmental interneurons serving larval and pupal mechanosensory reflexes in the moth Manduca sexta. J Comp Physiol [A] 171:195-205.

Warren JT, Gilbert LI (1986) Ecdysone metabolism and distribution during the pupal-adult development of Manduca sexta. Insect Biochem 16:65-82.

Weeks JC (1987) Time course of hormonal independence for developmental events in neurons and other cell types during insect metamorphosis. Dev Biol 124:163-176.

Weeks JC, Ernst-Utzschneider K (1989) Respecification of larval prolcg motor ncurons during metamorphosis of the tobacco hornworm, Manduca sexta: segmental dependence and hormonal regulation. J Neurobiol 20:569-592.

Weeks JC, Truman JW (1985) Independent steroid control of the fates of motoneurons and their muscles during insect metamorphosis. J Neurosci 5:2290-300.

Williams GJ, Caveney S (1980a) Changing muscle patterns in a segmental epidermal field. J Embryol Exp Morphol 58:13-33.

Williams GJ, Caveney S (1980b) A gradient of morphogenic information involved in muscle patterning. J Embryol Exp Morphol 58: 35-61.

Wright CD, Truman JW (1994) Steroid and neuronal regulation of the independent fates of nuclei of muscle DEO1 during metamorphosis in Manduca sexta. Soc Neurosci Abstr 20:1693. 